Çukurova Üniversitesi Mühendislik Mimarlık Fakültesi Dergisi, 34(4), ss. 217-223, Aralık 2019

Çukurova University Journal of the Faculty of Engineering and Architecture, 34(4), pp. 217-223, December 2019

\title{
Çok Amaçlı Baraj Haznelerinin Genetik Algoritma ile Enerji Üretimi Amaçlı Optimizasyonu
}

\author{
Recep YURTAL ${ }^{* 1}$ \\ ${ }^{1}$ Çukurova Üniversitesi, Mühendislik Fakültesi, Inşaat Mühendisliği Bölümü, Adana
}

Geliş tarihi: 06.09.2019Ｋabul tarihi: 20.12.2019

$\ddot{\mathbf{O z}}$

Çok amaçlı baraj haznelerinin diğer amaçlar kısıt olarak kullanıldığında hidroelektrik üretiminin optimizasyonu için farklı optimizasyon teknikleri uygulamada kullanılmaktadır. Bu araştırmada Evrim tabanlı programlardan Genetik Algoritma kullanılarak işletmedeki çok amaçlı bir barajın hidroelektrik enerji üretimi maksimize edilmiştir. Bu amaçla geliştirilen program kodu, içme suyu temini amacı da olan Seyhan Havzası'ndaki Karakuz Barajı ve HES haznesine uygulanmıș ve toplam enerji maksimize edilmiştir. Geliştirilen program ile elde edilen işletme politikası ile barajın fizibilite raporundaki toplam enerji yüzde on daha fazla üretilebilir hale gelmiştir. Çok amaçlı tek baraj için geliştirilen program, rahatlıkla çok amaçlı çok hazneli sistemler için geliştirilebilir. Geliştirilen program ve elde edilen eniyilenmiş işletme politikaları, ülkemizin enerji açığı ve küresel ısınmanın etkileri de düşünüldüğünde uygulayıcılara ve karar vericilere önemli katkılar sağlayacaktır.

Keywords: Hidroelektrik enerji optimizasyonu, Genetik algoritma, Çok amaçlı hazne

\section{Optimization of Multi-Purpose Reservoirs for Energy Production Using Genetic Algorithm}

\begin{abstract}
When other purposes of multi-purpose reservoirs are used as constraints, different optimization techniques are used for optimization of hydroelectric power generation. In this study, hydroelectric power generation of a multipurpose reservoir in the enterprise was maximized by using Genetic Algorithm from Evolution based programs. The program code developed for this purpose has been applied to the Karakuz Dam reservoir in the Seyhan River Basin, which has the purpose of supplying drinking water, and the total energy is maximized. With the operating policy achieved with the developed program, the total energy in the feasibility report of the dam has become more than ten percent more produced. Developed for a multi-purpose single reservoir, the program can be easily developed for multi-purpose multireservoir systems. The developed program and the optimized enterprise policies will contribute significantly to the implementers and decision makers considering the energy deficit and the effects of global warming.
\end{abstract}

Anahtar Kelimeler: Hydroelectric energy optimization, Genetic algorithm, Multipurpose reservoir

"Sorumlu yazar (Corresponding author): Recep YURTAL, ryurtal@cu.edu.tr 


\section{GİRIŞ̧}

Küresel isınmanın artan olumsuz etkileri ve ülkemizin gittikçe artan enerji açı̆̆ı, enerji kaynaklarının da verimli kullanılmasını zorunlu k1lmaktadır.

Yatırım ve işletme-bakım maliyetleri yüksek olan barajlar, içme suyu temini, sulama suyu temini, taşkın koruma, enerji üretimi gibi amaçlarla inşa edilmektedir. Aynı anda birden çok amaca hizmet etmek üzere tasarlanan barajlarda çok sayıda karar değişkeni ve kısıt bulunmaktadır. Çok sayıda kısıt ve karar değişkenine sahip çok amaçlı bir baraj veya barajlar sisteminde optimizasyon amaçlı kullanılabilecek, Doğrusal Programlama, Doğrusal Olmayan Programlama, Dinamik Programlama, Evrim Tabanlı Programlama (Genetik Algoritmalar, Genetik Programlama vb) gibi teknikler kullanılmaktadır. Her çoklu barajın amaç, kısıt ve karar değişkenleri birbirine benzese de amaçlardaki öncelikler kaynakların ve talebin özelliği gibi nedenlerle yerel farklılıklar söz konusudur. $\mathrm{Bu}$ nedenle her bir baraj için uygun teknikle ayrı modelleme yapmak zorunlu olmaktadır.

Uzun dönem için, baraj hazne işletmesi optimizasyonunda dinamik programlama Bellman [1], yaygın olarak kullanılmaktadır. Young [2], dinamik programlama ile tek baraj haznesi için optimal işletim kuralları geliştirmiştir. Larson [3], artımlı dinamik programlama ile çok hazneli problemi ele alan bir çalışma yapmıştır. Hall ve arkadaşları [4], artımlı dinamik programlamayı farklı bir şekilde iki hazneli probleme uygulamıştır. Heidari ve arkadaşları [5], artımlı dinamik programlamayı esas alarak kesintili türevsel dinamik programlamayı geliştirmiştir. Yurtal [6] çoklu baraj sistemlerinin enerji optimizasyonu için etkin bir artırımlı dinamik programlama modeli geliştirilmiş ve aşağı Seyhan Havzasındaki ardışık barajlara uygulamıştır. Genetik algoritma ilk olarak Holland [7] tarafindan geliştirilmiş, Goldberg [8] tarafından yaygınlaştırılmıştır. Holland [7] şema teoremi yoluyla genetik algoritmalar için teorik bir temel geliştirmeye çalışmıştır. Goldberg [8] ve Michalewicz [9], Genetik algoritma tanıtım ve uygulamaları ile ilgili birçok eser sunmustur. Esat ve Hall [10], genetik algoritmayı çok hazneli probleme uygulamış, haznelerdeki kısıtlarla, enerji üretimi ve sulama suyu temininden elde edilen faydaları maksimize etmeye çalışmıştır. Hınçal [11], çok hazneli sistemlere genetik algoritmayı uygulayarak enerjiyi eniyilemiştir.

Bu çalışmada, çok amaçlı bir barajın diğer amaçlar kısıt olarak kabul edilerek hidroelektrik üretimini maksimize eden eniyilenmiş işletme politikalarının belirlenmesi, beraberinde halen üretilmekte olan enerjinin artırılması amaçlanmıştır. Problemdeki fonksiyonların doğrusal olması veya olmamasından bağımsız olması nedeni ile Genetik Algoritmalar ile enerji optimizasyonu yapılmıştır.

\section{MATERYAL VE YÖNTEM 2.1. Materyal}

Dolsar [12,13] Çok amaçlı baraj haznelerinin diğer amaçlar kısıt olmak üzere, hidroelektrik enerji üretimi maksimizasyonu için geliştirilen programın uygulanması için, içme suyu amacı da olan enerji üretimi amaçlı Karakuz Barajı ve HES seçilmiştir. Geliştirilen program sonuçlarını karşılaștırabilmek için önce Karakuz Barajı ve HES'e ait 2008 tarihli fizibilite raporunda verilen değerler hiç değiştirilmeden kullanılmış, sonra raporda verilen değerler güncellenerek tekrar program uygulanmıştır.

\subsubsection{Karakuz Barajı ve HES}

Dolsar [13], Adana İli, Pozantı İlçesi, Çamlıbel (Karakuz) Mahallesi sınırları içerisinde, Körkün Çayı üzerinde, Karakuz Barajı ve Adana ili, Karaisalı İlçesi, Çukur Mahallesi sınırları içeresinde 76 MW kurulu gücünde Hidroelektrik Santral (HES) projelendirilmiştir (Şekil 1).

Dolsar [12], Yukarı Seyhan-Körkün Çayı Havzası; $37^{\circ} 08^{\prime}$ ile $38^{\circ} 00^{\prime}$ enlemleri, $34^{\circ} 50^{\prime}$ ile $35^{\circ} 13^{\prime}$ Doğu boylamlarının taradığı alan içinde yer alır. Kuzey-güney doğrultusunda boyu $98.5 \mathrm{~km}$ yağış alanı $1518 \mathrm{~km}^{2}$ 'dir (Şekil 1). Karakuz Barajı, maksimum su seviyesi (kontrolsüz dolusavak eşik seviyesi) $831 \mathrm{~m}$ olan, talvegten $32 \mathrm{~m}$ yüksekliğinde bir beton barajdır (Çizelge 1). 
Çizelge 1. Karakuz baraj haznesi proje Enerji formülünde ise: karakteristikleri $\left(\mathrm{m}^{3}\right)[12]$

\begin{tabular}{|l|r|}
\hline Minimum hazne hacmi & 1695000 \\
\hline Maksimum hazne hacmi & 5112000 \\
\hline Baraj aktif hacmi & 3417000 \\
\hline
\end{tabular}

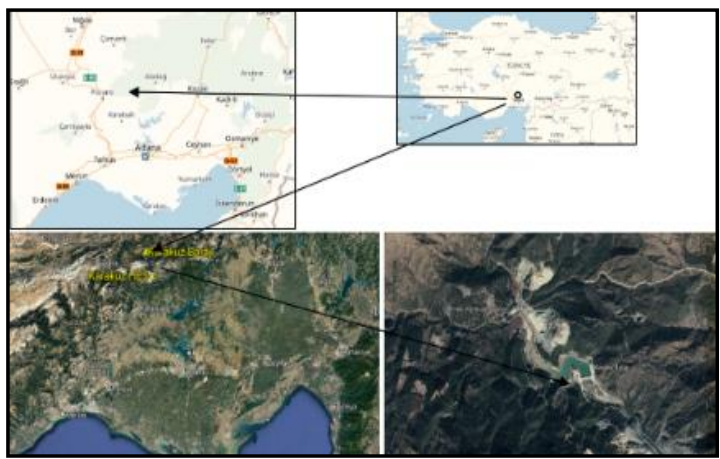

Şekil 1. Karakuz Barajı ve HES konumu

Dolsar [13], Karakuz santralı işletme çalışmalarında, gelecekte (2035-40 yılları) Nevşehir ili içmesuyu ihtiyacı olarak tahmin edilen 750 1/s debinin, 400 1/s'lik kısmının Karakuz Barajı membasından Körkün çayından alınacağı kabul edilmiştir (Çizelge 2).

Çizelge 2. Karakuz Barajı ve HES su alma yapısı ve su tahsisleri [12]

\begin{tabular}{|l|r|}
\hline Su alma yapısı kapasitesi $\left(\mathrm{m}^{3} / \mathrm{s}\right)$ & 16,41 \\
\hline Su alma yapısı girişi taban kotu $(\mathrm{m})$ & 813,5 \\
\hline (Karakuz baraj yeri) yıllık akım & 261,83 \\
\hline İçmesuyun için yıllık ortalama debi & 400 \\
\hline İçmesuyuna ayrılan yıllık akım & 12,61 \\
\hline Akarsu yatağında kalacak akım & 249,22 \\
\hline
\end{tabular}

Dolsar [12], cebri boru $1541 \mathrm{~m}$ uzunluğunda ve 2 $\mathrm{m}$ çapında olup, tünel çıkış portalinden hemen sonra başlamaktadır (Çizelge 3). Fizibilite çalışmalarında santralin işletme çalışmaları gelen suyun sabit bir yükseklikten düşürülmesi suretiyle yapılmıştır. Ortalama türbin verimi 0,89 ; maksimum türbin verimi 0,91 ; jeneratör verimi ise 0,98 alınarak güç formülündeki katsayı:

$0,91 \times 0,98 \times 9,8065=8,7454367$
$0,89 \times 0,98 \times 9,8065=8,5532293$ katsay1s 1 kullanılmıştır.

Çizelge 3. Karakuz Barajı santrali tesis özellikleri [12]

\begin{tabular}{|c|c|}
\hline Enerji iletim hattı tipi & Tünel ve çelik boru \\
\hline İletim hattı kapasitesi ve çap1 & $16,41 \mathrm{~m}^{3} / \mathrm{s}, \mathrm{D}=2,5 \mathrm{~m}$ \\
\hline İletim hattı çelik boru uzunl. & $5188 \mathrm{~m}$ \\
\hline T1 tüneli uzunluğu ve çap1 & $1700 \mathrm{~m}, \mathrm{D}=3,0 \mathrm{~m}$ \\
\hline Tz tüneli uzunluğu ve çap1 & $5200 \mathrm{~m}, \mathrm{D}=3,0 \mathrm{~m}$ \\
\hline $\begin{array}{l}\text { Ara tünellerin toplam } \\
\text { uzunlukl ve çap1 }(\mathrm{T} 3, \mathrm{~T} 4, \mathrm{Ts})\end{array}$ & $388 \mathrm{~m}, \mathrm{D}=3,0 \mathrm{~m}$ \\
\hline $\begin{array}{l}\text { İletim hatlarının toplam } \\
\text { uzunluğu(cebri boru hariç) }\end{array}$ & $12476 \mathrm{~m}$ \\
\hline $\begin{array}{l}\text { Cebri boru uzunluğu, } \\
\text { sayıs1 ve çap1 }\end{array}$ & $\begin{array}{r}1541 \mathrm{~m} \\
(1 \mathrm{ad} . ; 2,0 \mathrm{~m})\end{array}$ \\
\hline Santral çıkıșında su kotu & $258,0 \mathrm{~m}$ \\
\hline Brüt düşü & $570,8 \mathrm{~m}$ \\
\hline Toplam santral debisi & $\begin{array}{r}16,41 \mathrm{~m}^{3} / \mathrm{s} \\
\left(2 \times 8,2 \mathrm{~m}^{3} / \mathrm{s}\right)\end{array}$ \\
\hline Santral kurulu gücü & $\begin{array}{r}76 \mathrm{MW} \\
(2 \mathrm{X} 38 \mathrm{MW})\end{array}$ \\
\hline
\end{tabular}

Dolsar [12], fizibilite raporunda, debi süreklilik eğrisinden akarsuda zamanın $\% 5$ 'inde $25 \mathrm{~m}^{3} / \mathrm{s}$ ve altında; zamanın $\% 25$ 'inde $11 \mathrm{~m}^{3} / \mathrm{s}$ ve altında, zamanın \%95'inde mevcut olan (güvenilir) debi ise $1,51 \mathrm{~m}^{3} / \mathrm{s}$ 'dir. Karakuz santralinin biriktirmesiz olarak yapılacak işletme çalışmalarında firm (güvenilir) enerji üretiminde yukarıdaki debi dikkate alınmıştır. Ancak, bu debiden de gelecekte Nevşehir içmesuyu ihtiyacı için çekilecek ortalama 400 1/s içmesuyu debisi çıarıldığında Karakuz santralindan (günlük 24 saate göre) türbinlenecek asgari debi $1,11 \mathrm{~m}^{3} / \mathrm{s}$ olmaktadır.

Dolsar [12], fizibilite raporundaki enerji üretim tahminleri Çizelge 4'te verilmiştir.

Çizelge 4. Karakuz Barajı enerji üretim tahminleri [12]

\begin{tabular}{|l|c|}
\hline \multicolumn{2}{|c|}{$\begin{array}{c}\text { Nevşehir içmesuyu ihtiyacı için 400 l/s ve } \\
\text { ekolojik olarak 100 l/s su çekilmesi hali }\end{array}$} \\
\hline Güvenilir güç & $5,03 \mathrm{MW}$ \\
\hline Yıllık güvenilir enerji üretimi & $40,90 \mathrm{GWh}$ \\
\hline Yıllık sekonder enerji üretimi & $248,61 \mathrm{GWh}$ \\
\hline Yıllık toplam enerji üretimi & $289,51 \mathrm{GWh}$ \\
\hline
\end{tabular}


Karakuz baraj yerinde drenaj alanı $1278 \mathrm{~km}^{2}$ 'dir ve tesis yerinde 1830 no'lu Akım Gözlem İstasyonu (AGİ) vardır. Fizibilite raporunda, Baraj yerindeki 1830 no'lu AGİ'nin 1993-2006 yılları için var olan kayıtları, aralarında \%94,5 korelasyon katsayısına sahip olması nedeniyle 1970-2006 yılları kayıtlı akımları bulunan 1820 no'lu AGí değerleri kullanılarak 1970 yılına kadar uzatılmıştır.

Dolsar [12], baraj yeri buharlama değerleri için Karaisalı Devlet Meteoroloji İstasyonu (DMI) 1993-2007 yılı Toplam Buharlaşma kayıtları kullanılmıştır.

\subsection{Yöntem}

Genetik Algoritma, ilk olarak 1975'te John Holland [7] tarafindan önerilen, daha sonra geliştirilen, doğal evrim sürecini esas alan bir optimizasyon tekniğidir. Biyolojik olarak Gen, canlıların karakterlerini belirleyen en küçük kalıtsal birim; Kromozom (birey), birçok genin bir araya gelerek oluşturduğu dizi; Popülasyon ise kromozomlardan oluşan topluluktur.

Goldberg, [8], Hınçal, [11] genetik algoritma, doğal seleksiyon ve doğal genetik mekaniğine dayalı bir arama algoritmasıdır. Adının da ifade ettiği üzere, genetik algoritma, doğal evrim ve en iyinin hayatta kalması ilkelerine dayalıdır. Genetik algoritmalarda, problemin aday çözümlerinin popülasyonu kullanılır. Genetik algoritmalar, eşzamanlı olarak problemin birden çok aday çözümünü dikkate alır ve bu çözümler popülasyonunu global optimuma doğru hareket ettirerek ilerler.

Hınçal, [11] genetik algoritma, ana nesil süreci döngüsüne sahiptir. Bu döngü, esas olarak nesil sayısıyla yönetilir. Bu döngü içinde, bir başlangıç popülasyon oluşturulur; her birey sayısal olarak ifade edilebilecek şekilde kodlanır; ardından popülasyonun her bireyine, sonraki nesillerde yaşayıp yaşamayacağını değerlendirmek üzere kullanılacak bir parametre olan bir uygunluk değeri atanır. Sonraki nesilde yaşamaya hak kazanacak bireyin değerlendirilmesi ve seçimi, seçim (seleksiyon), çaprazlama ve mutasyon adı verilen genetik operatörler sayesinde gerçekleştirilir.

\subsubsection{Genetik Algoritma ile Çok Amaçlı Baraj Haznelerinin Yillık Toplam Hidroelektrik Enerji Maksimizasyonu}

Çok amaçlı barajların optimal işletmesinde, sulama suyu temini, içme suyu temini, sanayi suyu temini gibi amaçlar için hazneden çekilecek minimum debiler kısıt olarak alınmak üzere üretilecek yıllık toplam enerji maksimize edilmiştir.

Amaç fonksiyonu (Eşitlik 1, 2 ve 3):

$\operatorname{Max} \sum_{i=1}^{T} E_{i}$

$\mathrm{E}_{\mathrm{i}}=\mathrm{P}_{\mathrm{i}} \times \mathrm{t}$

$P_{i}=\rho \cdot g \cdot \eta \cdot Q_{i} \cdot H_{i}$

Burada, $\mathrm{T}$ seçilen zaman periyoduna göre toplam zaman dilimi, Ei (Wh) ise her bir zaman periyodunda üretilecek hidroelektrik enerji, $\mathrm{P}_{\mathrm{i}}$ her bir zaman periyodunda üretilecek güç $(\mathrm{W}), \mathrm{H}_{\mathrm{i}}$ ise $\mathrm{i}$ ninci zaman periyodundaki net düşü $(\mathrm{m}), \eta$ toplam randıman, $\rho$ yoğunluk $\left(\mathrm{kg} / \mathrm{m}^{3}\right)$, g yer çekimi ivmesi $\left(\mathrm{m} / \mathrm{s}^{2}\right)$, $\mathrm{t}$ ise zamandir $(\mathrm{h})$.

Süreklilik denklemi ise (Eşitlik 4 ve 5);

$\mathrm{S}_{\mathrm{i}+1}=\mathrm{S}_{\mathrm{i}}+\mathrm{I}_{\mathrm{i}}-\mathrm{Q}_{\mathrm{i}}-\mathrm{Ev}_{\mathrm{i}}$

$\mathrm{Ev}_{\mathrm{i}}=\mathrm{B}_{\mathrm{i}} \times \mathrm{A}_{\mathrm{i}}$

Burada zaman periyoodu (ay) olarak alınırsa; $\mathrm{S}_{\mathrm{i}}$ ve $\mathrm{S}_{\mathrm{i}+1}$, $\mathrm{i}$ ve $\mathrm{i}+1$ inci zaman diliminde hazne hacmi $\left(10^{6} \mathrm{~m}^{3} / \mathrm{ay}\right), \mathrm{I}_{\mathrm{i}}$, $\mathrm{i}$ ninci zaman diliminde hazneye giren akım $\left(10^{6} \mathrm{~m}^{3} / \mathrm{ay}\right), \mathrm{Q}_{\mathrm{i}}$, i ninci zaman diliminde hazneden amaçlar (enerji üretimi, içme suyu temini, sulama suyu temini, çevresel akış vb) için çekilecek akım( $\left(10^{6} \mathrm{~m}^{3} / \mathrm{ay}\right), \mathrm{Ev}_{\mathrm{i}}$, i ninci zaman dilimindeki buharlaşma miktarı $\left(10^{6} \mathrm{~m}^{3} / \mathrm{ay}\right), \mathrm{Bv}_{\mathrm{i}}$, i ninci zaman dilimindeki noktasal buharlaşma miktarı $(\mathrm{mm}), \mathrm{A}_{\mathrm{i}}$, i ninci zaman dilimindeki göl yüzeyi alanıdır $\left(10^{6} \mathrm{~m}^{3} /\right.$ ay $)$. 
Kisitlar:

Hazne hacmi $\left(\mathrm{S}_{\mathrm{i}+1}\right)$, $\mathrm{i}+1$ ninci zaman diliminde minimum işletme hacmine eşit veya büyük, maksimum işletme hacminden küçük veya eşit olmalıdır (Eşitlik 6).

$\mathrm{S}_{\min } \leq \mathrm{S}_{\mathrm{i}+1} \leq \mathrm{S}_{\max }$

Hazneden amaçlar için çekilecek akım $\left(\mathrm{Q}_{\mathrm{i}}\right)$, i ninci zaman diliminde ihtiyaca göre belirlenecek minimum ve maksimum değerler arasında olmalıdır (Eşitlik 7).

$\mathrm{Q}_{\min } \leq \mathrm{Q}_{\mathrm{i}} \leq \mathrm{Q}_{\max }$
Ayrıca Cebri Boru kapasiteleri ve Güvenilir (firm) enerji de kısıt olarak kullanılmıştır. Minimum hazne hacmi kısıtı için sonsuz değere sahip ceza fonksiyonu tanımlanırken, diğer her bir kısıt için dinamik ceza fonksiyonları tanımlanmıştır. Kısıtlar için membadaki içmesuyu ihtiyacı ve ekolojik akım giren akımdan çıkartıldıktan sonra optimizasyon gerçekleştirilmiştir.

Amaç fonksiyonunun optimizasyonu için Genetik Algoritmalar tekniği kullanılmıştır (Şekil 2). Bu amaçla toplam enerjiyi maksimize edecek bir MATLAB kodu yazılmıştır. Yazılan kod farklı popülasyon ve generasyon (iterasyon) sayıları ile defalarca denenmiştir.

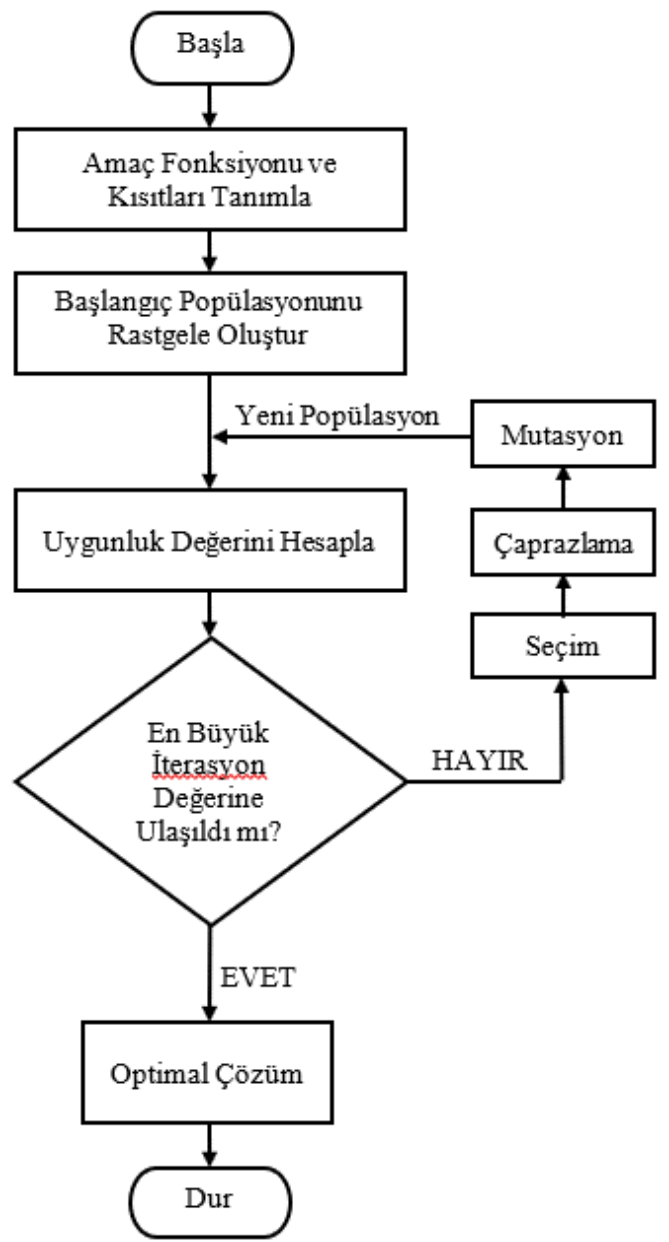

Şekil 2. Genetik algoritma ile optimizasyon akış şeması 


\section{BULGULAR VE TARTIŞMA}

Çok amaçlı bir barajın Genetik Algoritma yöntemi ile yillı toplam enerji maksimizasyonu için geliştirilen matlab kodu, sonuçların karşılaştırılabilmesi açısından "Yukarı Seyhan Körkün Havzası Karakuz Barajı ve Hidroelektrik Santralı Fizibilite Raporu (DOLSAR, [12])" verileri değiştirilmeden kullanılarak çalıştırılmıştır. Geliştirilen kod, enerji üretimi harici amaçları kısıt olarak kabul ettiğinden, sadece içmesuyu kısıtının olduğu durum için uygulanmıştır.

Fizibilite raporunda günlük akım değerleri ile enerji üretimi hesaplanmıştır. $\mathrm{Bu}$ çalışmada ise geliştirilen kodun uygulanabilirliği araştırıldığından, Fizibilite Raporunda verilen 1970-2006 yılları arası aylık akım değerleri kullanılmıştır.

Geliştirilen kod "Population Size" 100-400, "Maximum Generations" 100-500, "Maximum Stall Generations" 100-400 arasında seçilerek defalarca çalıştırılıp denenmiş, sonuçların karşılaştırılması ile sonucu etkilemeyecek ve işlem zamanından tasarruf edecek şekilde bu projedeki probleme özel olmak üzere "Population Size" 250, "Maximum Generations" 300, "Maximum Stall Generations" 300 olarak seçilmiştir.

Geliștirilen kod ile önce, 1970-2006 yılları arası tüm yıllar kullanılarak aylık akımlarla program çalıştırılmıştır. Her çalıştırmada farklı karar değişkeni popülasyonu türetildiğinden, sonuçlar birbirinden farklı çıkabilmektedir. $\mathrm{Bu}$ nedenle işlem zamanı oldukça uzun süren bu tür uygulamada yapılan optimizasyonu karşılaştırmak üzere, program kodunda değişiklik yapılmış ve her yıl bağımsız olarak çalıştırılıp, optimize edilmiş sonuçlarla bir sonraki ardişık yıl optimize edilmiştir. $\mathrm{Bu}$ uygulamada optimizasyon sonucu fizibilite raporuna göre ilk uygulamalarda $\% 1$ daha fazla enerji tahmini yapmıştır.

Nevşehir içmesuyu ihtiyacı için 400 1/s ve ekolojik olarak 100 1/s su çekilmesi hali için Karakuz Barajı Enerji Üretim Tahminleri (DOLSAR, [12]) ve Genetik Algoritma ile Optimizasyon sonucu üretilen Yıllık Toplam Enerji karşılaştırıldığında yaklaşık \%1 lik bir artış bulunmuştur (Çizelge 5).

Çizelge 5. Fizibilte raporu ve geliştirilen genetik algoritma optimizasyon modeli sonuçları

\begin{tabular}{|l|c|c|}
\hline & $\begin{array}{c}\text { Fizibilite Raporu } \\
\text { (DOLSAR [12]) }\end{array}$ & $\begin{array}{c}\text { Genetik } \\
\text { Algoritma ile } \\
\text { Optimizasyon } \\
\text { Sonucu }\end{array}$ \\
\hline $\begin{array}{l}\text { Y1llik toplam } \\
\text { enerji üretimi } \\
\text { (GWh) }\end{array}$ & 289,51 & 292,375 \\
\hline
\end{tabular}

Geliştirilen program ile tüm kısıtlar, en kurak dönemler de dahil olmak üzere tüm zaman dilimlerinde rahatlıkla karşılanabilmektedir.

Optimize edilen sonuç, mevcuda göre \%1 daha iyidir; ancak muhtemelen günlük veriler kullanılsa idi sonuçlar daha farklı olacaktı. Ayrıca seçilen baraj yaklaşık $32 \mathrm{~m}$ yüksekliğinde nispeten küçük bir barajdır ve fizibilite çalışmalarında maksimum kotta çalıştırılması hedeflenmiştir. Geliştirilen kod çok küçük müdahalelerle farklı barajlara uygulanabilir durumdadır. Geliştirilen Genetik Algoritma Modeli farklı çok amaçlı (sulama, içme suyu, taşkın vb) barajlara uygulanarak sonuçların karşılaştırılması daha uygun olacaktır.

\section{SONUÇ VE ÖNERÍLER}

Çalışmada, çok amaçlı bir barajın diğer amaçlar kısıt olarak kabul edilerek hidroelektrik üretimini maksimize eden eniyilenmiş işletme politikalarının belirlenmesi, beraberinde halen üretilmekte olan enerjinin artırılması amaçlanmıştır.

Projede amaçlandığı üzere Genetik Algoritma ile Çok Amaçlı Barajların yıllık toplam enerji maksimizasyonu için matlab program kodu geliştirilmiş ve Karakuz Barajı ve HES'e uygulanmıştır. Uygulama ile yıllık toplam enerji maksimize edilerek eniyilenmiş işletme politikaları belirlenmiş, yaklaşık \%1'lik enerji artışı sağlanmıştır.

Çalışma kapsamında geliştirilen Genetik Algoritma ile Çok Amaçlı Barajların yıllık toplam 
enerji maksimizasyonu program kodu çok küçük müdahalelerle farklı barajlara uygulanabilir olduğu gibi, çok amaçlı ardışık çoklu barajlar için de modifiye edilerek geliştirilebilir.

Programın uygulanması sonucu üretilecek işletme politikalarının, uygulayıcı mühendislere karar verme aşamasında önemli katkılar sağlayacağı düşünülmektedir.

Araştırmacının daha önceki çalışmalarında geliştirdiği "Yurtal [6,14], çoklu baraj sistemlerinin enerji optimizasyonu için geliştirilmiş etkin bir artırımlı dinamik programlama modeli” ile kıyaslama yapıldığında, Dinamik Programlama modeli sonuçlarının daha uygun sonuçlar vereceği düşünüldüğünden, bundan sonraki aşamada aynı barajlara her iki modelin uygulanarak sonuçlarının karşılaştırılması hedeflenmektedir. Bunun için öncelikle bu proje kapsamında tek bir baraj için geliştirilen modelin çoklu ardışık barajlar için modifiye edilmesi gerekmektedir.

\section{TEŞEKKÜR}

$\mathrm{Bu}$ çalışma, Çukurova Üniversitesi Bilimsel Araştırma Projeleri Koordinasyon Birimi (Proje No: FBA-2017-8295) tarafından desteklenmiştir.

\section{KAYNAKLAR}

1. Bellman, R., 1957. Dynamic Programming, Princeton University Press, Princeton, N.J. (2)

2. Young, G.K., 1967. Finding Reservoir Operating Rules, J. Hydr. Div., ASCE, 93(6), 297-321.

3. Larson, R.E., 1968. State Increment Dynamic Programming, Elsevier Science, New York.

4. Hall, W.A., Harboe, W., Yeh, W.W.G., Askew, A.J., 1969. Optimum Firm Power Output from a Two Reservoir System by Incremental Dynamic Programming, Water Resour. Ctr. Contrib., University of Calif., 130, 273-282.

5. Heidari, M., Chow, V., Kotovic, P., Meredith, D., 1971. Discrete Diff Erential Dynamic Programming Approach to Water Resources
System Optimization, Water Resour. Res, 7(2), 273-282.

6. Yurtal, R., 1993. Çoklu Baraj Sistemlerinin Enerji Optimizasyonu İçin Geliştirilmiş Etkin bir Artırımlı Dinamik Programlama Modeli ve Aşağı Seyhan Havzası'na Uygulanması, Doktora Tezi, Çukurova Üniversitesi Fen Bilimleri Enstitüsü, s101, Adana.

7. Holland, J.H., 1975. Adaptation in Natural and Artificial Systems, MIT Press, Cambridge, Mass.

8. Goldberg, D., 1989. Genetic Algorithms in Search Optimization and Machine Learning, Addison-Wesley, Reading, Mass.

9. Michalewicz, Z., 1992. Genetic Algorithms+ Data Structures=Evolution Programs, Springer, New York.

10. Esat, V., Hall, M.J., 1994. Water Resources System Optimization using Genetic Algorithms, Proc. $1^{\text {st }}$ Int. Conf. Hydroinform. Balkema, Potterdam, the Netherlands, 225-231.

11. Hınçal, O., 2008. Optimization of Multireservoir Systems by Genetic Algorithm, PhD Dissertation, Middle East Technical University, 97, Ankara.

12. DOLSAR, Mühendislik Limited Şirketi, 2008. Yukarı Seyhan-Körkün Havzası Karakuz Barajı ve Hidroelektrik Santralı Fizibilite Raporu, Ankara.

13. DOLSAR, Mühendislik Limited Şirketi, 2011. Karakuz Barajı ve HES Gerekçe Raporu, Ankara.

14. Yurtal, R., Seckın, G., Ardiclıoglu, M., 2005. Hydropower Optimization for the Lower Seyhan Basin System in Turkey Using Dynamic Programming, Water International, 30(4), 522-529. 
